\title{
DOS INTERESANTES SENTENCIAS A PROPÓSITO DE LA POSIBILIDAD DE PATENTAR EMBRIONES Y GENES
}

\author{
TWO INTERESTING SENTENCES REGARDING TO THE POSSIBILITY \\ OF PATENTING GENES AND EMBRYOS
}

Ronald Cárdenas Krenz ${ }^{1}$

\section{RESUMEN}

El artículo trata sobre dos importantes sentencias dadas en Europa y en Estados Unidos en los años 2011 y 2013, respectivamente, que declaran la imposibilidad de patentar embriones $y$ genes.

Palabras Claves: Bioética, Biotecnología, Patentes de embriones.

\begin{abstract}
The article discusses two important sentences given in Europe and the United States in 2011 and 2013, respectively, declaring the impossibility of patenting genes and embryos.
\end{abstract}

Key Words: Bioethics, Biotechnology, Embryos patents

Uno de los temas más delicados vinculados con las industrias biotecnológicas es, sin ninguna duda, el de la posibilidad de patentar embriones y genes, teniendo en cuenta su naturaleza e implicancias.

Sobre el particular, una interesante sentencia del Tribunal de Justicia de la Unión Europea, ha resuelto, en octubre de 2011, que no se pueden patentar las células madre obtenidas de embriones humanos ni sus materiales biológicos derivados, pues ello atentaría contra la dignidad humana. Esto, independientemente de que exista un fin comercial, industrial o de investigación.

\footnotetext{
1 Profesor de las Facultades de Derecho de la UNIFE, Universidad de Lima y ESAN. Decano de la Facultad de Derecho de la Universidad Femenina del Sagrado Corazón. Ha sido Miembro del Comité de Bioética de la Facultad de Biología de la Universidad Nacional Mayor de San Marcos. Académico Correspondiente de la Academia Nacional de Derecho y Ciencias Sociales de Córdoba (Argentina). Profesor Honorario de la Universidad Nacional San Agustín y de la Universidad César Vallejo. Miembro Co-fundador de la Cátedra UNESCO en Bioética y Biojurídica en el Perú. Ha sido corresponsal en nuestro país de la revista Perfiles Liberales (Colombia) y Perfiles del Siglo XXI (México), así como Moderador internacional de seminarios de la fundación alemana Friedrich Naumann.

Fecha de recepción: 30 de octubre de 2013.

Fecha de aceptación: 05 de noviembre de 2013. 
¿Qué quiere decir esto? Pues muchas cosas. Veamos, por ejemplo: Desde hace unos años existe un gran interés por el uso de células madre para su aplicación a fin de hacer frente a diversas enfermedades; siendo los embriones una de las fuentes principales para poder conseguirlas (en realidad su efectividad es discutible, mas dejemos el tema para otro momento), los cuales se pueden crear en el laboratorio para luego proceder a extraerles dichas células; esto implica disponer de la vida del embrión (aunque hay quienes están trabajando en poder extraer células madre del mismo sin acabar con su vida, pero es sumamente complicado y de todos modos riesgoso). Entonces, una vez obtenidas dichas células madre, supongamos que un científico que trabaja en biotecnologías, las procesa en el laboratorio para obtener determinadas células depuradas y listas para su "uso", patentando tanto lo que ha podido obtener como el procedimiento empleado, ya sea para poder lucrar con ello, registrarlo simplemente para que quede como una creación suya o a fin de ponerlo a disposición para quien quiera usarlo para determinadas investigaciones. Pues bien, con la sentencia bajo comentario, esto no será posible.

Siendo la referida declaración muy importante de por sí, no lo es menos el hecho que la sentencia defina al embrión como todo óvulo humano a partir del estadio de la fecundación, incluyendo también todo óvulo humano no fecundado en el que se haya implantado el núcleo de una célula humana madura y todo óvulo humano no fecundado estimulado para dividirse y desarrollarse mediante partenogénesis.

Así, un óvulo no fertilizado que haya sido manipulado científicamente y, por ello, esté "en disposición de iniciar el proceso de desarrollo de un ser humano", debe ser considerado como un embrión, mereciendo protección legal para todos los efectos.

La sentencia, recaída en el asunto C-34/10, fue dada a raíz del caso de un ciudadano alemán ${ }^{2}$ que en 1997 registró una patente de células progenitoras neuronales aisladas y depuradas, obtenidas a partir de células madre embrionarias humanas (incluyendo sus procedimientos de producción), cuyo uso iba destinado a tratar enfermedades neurológicas. Frente a este hecho, la conocida organización. Greenpeace, oponiéndose a la comercialización del cuerpo humano, pidió a la justicia alemana la nulidad de la patente; este pedido motivó que el Tribunal Federal de Justicia alemán planteara una consulta al tribunal europeo, motivo por el cual emitió la referida sentencia. ${ }^{3}$

3 Oliver Brüstle, Director del Instituto de Neurobiología Reconstructiva de la Universidad de Bonn.

Sobre las consecuencias que, por ejemplo, tiene el pronunciamiento de dicho Tribunal para el Derecho español, afirma 
Cabe señalar que las normas europeas sobre patentes impiden registrar cualquier invención que vaya contra la moral o las buenas costumbres; en esa línea, existe la Directiva 98/44/CE, comprendiendo expresamente el uso de embriones humanos; además, es de recordar que, de acuerdo a los criterios de patentabilidad del Derecho de Patentes, un simple descubrimiento no puede ser objeto de una patente.

No es por tanto factible que, a través de la manipulación genética, un científico "cree" unos "super-embriones" con determinadas características físicas (incluyendo por ejemplo propiciar que sea más fuerte, más resistente para ciertas condiciones climáticas, que desarrolle cierta estatura, etc.) y luego pretender venderlo a otras personas que desearan también poder tener un "super-hijo", u ofrecerlo a un gobierno que desee poder contar con un ejército compuesto por un determinado tipo de soldados. La sentencia del Tribunal de Justicia que comentamos refuerza en este extremo lo ya reconocido por la citada directiva.

Otro detalle a anotar es que la sentencia no se extiende a las células madre de origen adulto y sus derivados, y es que ellas tienen una naturaleza distinta, por lo que queda siempre disponible esta vía de investigación que, incluso, hoy en día, desde un punto de vista estrictamente científico, se presenta en Europa como más promisoria que el uso de las células madre provenientes de embriones. Justamente, en el año 2012, el Premio Nobel de Medicina fue entregado a los investigadores John Gurdon y Shinya Yamanaka que, a través de la reprogramación celular, han podido obtener células madre de adultos evitando el problema ético de disponer de embriones humanos para conseguirlas.

Queda claro también que esta exclusión de los embriones humanos que hace la sentencia, no afecta a las invenciones técnicas que tengan un objetivo terapéutico o de diagnóstico que se apliquen en beneficio del propio embrión, lo que vendría a ser una justa aplicación del principio de beneficencia, que ha sido ampliamente desarrollado por la Bioética.

Naturalmente que uno de los "costos" de decisiones de este tipo, como han señalado diversos analistas, tiene que ver con que se reduzcan los incentivos para la investigación, al no poder las empresas biotecnológicas generar recursos con los resultados de este tipo de investigaciones, lo que motivaría problemas de competitividad de los europeos frente a los norteamericanos. 
Para mayor detalle, es interesante transcribir la siguiente declaración final con la que concluye esta significativa sentencia:

"En virtud de todo lo expuesto, el Tribunal de Justicia (Gran Sala) declara:

1) El artículo 6, apartado 2, letra c), de la Directiva 98/44/CE del Parlamento Europeo y del Consejo, de 6 de julio de 1988, relativa a la protección jurídica de las invenciones biotecnológicas, debe interpretarse en el sentido de que:

- Constituye un «embrión humano» todo óvulo humano a partir del estadio de la fecundación, todo óvulo humano no fecundado en el que se haya implantado el núcleo de una célula humana madura y todo óvulo humano no fecundado estimulado para dividirse y desarrollarse mediante partenogénesis.

- Corresponde al juez nacional determinar, a la luz de los avances de la ciencia, si una célula madre obtenida a partir de un embrión humano en el estadio de blastocisto constituye un "embrión humano» en el sentido del artículo 6, apartado 2, letrac), de la Directiva 98/44.

2) La exclusión de patentabilidad en relación con la utilización de embriones humanos con fines industriales o comerciales contemplada en el articulo 6, apartado 2, letrac), de la Directiva 98/44 también se refiere a la utilización con fines de investigación científica, pudiendo únicamente ser objeto de la solicitud de patente la utilización con fines terapéuticos o de diagnóstico que se aplica al embrión y quele es útil.

3) El artículo 6, apartado 2, letra c), de la Directiva 98/44 excluye la patentabilidad de una invención cuando la información técnica objeto de la solicitud de patente requiera la destrucción previa de embriones humanos o su utilización como materia prima, sea cual fuere el estadio en el que éstos se utilicen y aunque la descripción de la información técnica reivindicada no mencione la utilización de embriones humanos."

La referida instancia esgrime que el legislador europeo quiso excluir toda posibilidad de patentabilidad de un embrión en tanto pudiera afectar el respeto a la dignidad humana. $Y$, como sabemos, las normas europeas niegan la posibilidad de patentes que vayan contra la moral y las buenas costumbres.

Naturalmente que el hecho que la citada sentencia declare que hablamos de la existencia de un ser humano desde la fecundación no hace sino confirmar algo que ha sido ampliamente sustentado en la doctrina, revelando que la idea no es un simple postulado filosófico o una cuestión de fe, sino la 
constatación de un hecho científico; estamos ante un proceso de interacción mutua entre dos gametos (el femenino y el masculino) con el que se inicia el ciclo vital del ser humano que, como ser vivo, tiene la capacidad de movimiento desde sí mismo, en una unidad biológica intrínseca que tiene su propia finalidad, sobre la base de su autogobierno ${ }^{4}$ para regular su desarrollo en una dirección determinada por él mismo, en el que no se agrega nada nuevo una vez formado el cigoto.

Así, el ser humano es el resultado de un proceso de autoorganización del material biológico resultante de dicha fusión de gametos, orientado al desarrollo de un organismo completo, siguiendo la trayectoria vital que se genera con la fecundación, en una existencia continuada en el espacio y en el tiempo. $^{5}$

Adicionalmente, cabe recordar que el concepto de que la vida empieza con la concepción, hạ sido reiterado también en el Perú a través del Tribunal Constitucional, en su sentencia respecto a la aplicación de la píldora del día siguiente, expedida el 16 de octubre del año $2009 .^{6}$

\section{Volviendo al tema de la sentencia europea, en Estados Unidos, históricamente, el tratamiento de la materia ha sido diferente, pues allí sí se}

Corral García que: “Desde un punto de vista terminológico, es evidente que supone una desautorización en toda regla al legislador español, en concreto respecto a las definiciones y estatuto jurídico del embrión humano existentes en la Ley de técnicas de reproducción humana asistida -Ley 14/2006, de 26 de mayo (LRA) - y en la Ley de investigación biomédica" Corral García, Eduardo. "El lenguaje bioético en la normativa y jurisprudencia sobre problemas biojurídicos". En: Cuadernos de Bioética XXIV 2013/2. Tomado de: http://www.aebioetica.org/revistas/2013/24/81/239.pdf, p. 242)

4 “Como todo ser vivo, posee una unidad intrínseca en donde las partes están en función del todo en orden a vivir y con la posibilidad de transmitir vida. La heterogeneidad de las partes hace del embrión desde su inicio un pequeño organismo con la cualidad de moverse a sí mismo". Pastor García, Luis Miguel. "La ciencia y la bioética en el debate embrionario". Artículo publicado en Verdad.es, Murcia, 15.11.2008:

http://www.laverdad.es/murcia/prensa/20081115/opinion/ciencia-bioetica-debate-embrionario-20081115.html. "El cigoto es el punto exacto en el espacio y en el tiempo en que un 'individuo humano' inicia su propio ciclo vital". Serra, A. "Dignidad del embrión humano", en: Consejo Pontificio Para La Familia, Lexicón. Términos ambiguos y discutidos sobre familia, vida y cuestiones éticas, Madrid: Palabra, 2004.

5

López Moratalla, Natalia; Esteban Santiago y Gonzalo Herranz Rodríguez. "Inicio de la vida de cada ser humano. ¿Qué hace humano el cuerpo del hombre?, En: Cuadernos de Bioética XXII, 2011/2, p. 286, 287, 288 y 298. Como señalan Aznar y Pastor, "la capacidad de interacción muestra un todo orgánico que posee una unidad y responde al ambiente desde él mismo, cuando un conglomerado solo mostraría respuestas independientes y sin orden entre sí". Aznar, Justo y Luis Miguel Pastor. "Estatuto biológico del embrión humano". Tomado de: http://intranet.usat.edu.pe/aulavirtual/file.php/6698/Material_Estatuto_embrion/3.pdf, p.4.

6.

6 “... este Colegiado se decanta por considerar que la concepción de un nuevo ser humano se produce con la fusión de las células materna y paterna con lo cual se da origen a una nueva célula que, de acuerdo al estado actual de la ciencia, constituye el inicio de la vida de un nuevo ser. Un ser único e irrepetible, con su configuración e individualidad genética completa y que podrá, de no interrumpirse su proceso vital, seguir su curso hacia su vida independiente. La anidación e implantación, en consecuencia, forma parte del desarrollo del proceso vital, mas no constituye su inicio". Véase el texto completo de la sentencia en: http://www.tc.gob.pe/jurisprudencia/2009/02005-2009-AA.html. 
permite la patente de células madre embrionarias humanas e, incluso, los investigadores que las usan, deben pagar los derechos correspondientes al científico que las descubrió.

Por ello, y por la dimensión que tiene el mercado de empresas biotecnológicas en EE.UU., resulta también muy importante la noticia de la expedición de una reciente sentencia en dicho país, el 13 de junio del 2013, por la que el Tribunal Supremo norteamericano ha dictaminado que el ADN en la naturaleza o aislado no se puede patentar. Así, queda establecido -por unanimidad-, que no son patentables los genes humanos, resolviendo que la empresa Myriad Genetics no tiene derecho a la propiedad industrial y la explotación comercial exclusiva de los genes BRCA1 y BRCA2, cuyo análisis sirve para evaluar el riesgo de desarrollar cáncer de mama y ovario.

El proceso se inició a partir de un reclamo presentado en el año 2009 por la Fundación Patentes Públicas (Patent Public Foundation, PubPat) y la Unión Estadounidense por las Libertades Civiles (American Civil Liberties Union, $\mathrm{ACLU})$, con el apoyo de asociaciones de pacientes de cáncer de mama y colectivos de médicos, quienes solicitaron se declare inválidas e inconstitucionales las patentes registradas por Myriad, propiedad que impedía que un paciente pueda tener otra opinión sobre riesgo de cáncer. ${ }^{7}$

Como destacan Jaime Prats y Carolina García Valencia, la resolución judicial supone un cambio radical en las reglas de juego existentes hasta el momento, lo que tendrá previsiblemente importantes consecuencias en Estados Unidos. ${ }^{8}$ Vale decir que dicho país ha sido más bien siempre abierto a las patentes a ultranza, en contraste con el criterio más restrictivo y prudente de Europa. ${ }^{9}$

${ }^{7}$ El proceso se inició cuando el genetista Harry Ostrer, de la Universidad Yeshiva y del Einstein College of Medicine de Nueva York, aisló especímenes del BRCA para ser secuenciados. Myriad Genetics, quien tiene un negocio de unos US \$ 450 millones al año, amenazó con demandarlo. Ostrer, con el apoyo de la Unión Americana por las Libertades Civiles (ACLU) y la Fundación Pública de Patentes de Nueva York, inició el juicio contra Myriad, que con un monopolio de 15 años cobra más de US $\$ 3.000$ por prueba del BRCA.

En el 2010, una Corte Federal de Nueva York sentenció a favor de ACLU, pero Myriad apeló con éxito. Finalmente el juicio llegó a la Corte Suprema con el resultado a favor de Orstrer (Unger, Tomás. "Los genes y las patentes". En: Diario El Comercio. Lima, edición del 09.07.2013, p. A 14).

8 Para más detalle, véase la nota: "El Tribunal Supremo de EE UU dictamina que el ADN en la naturaleza o aislado no es patentable. Rompe la exclusividad en los test de detección de enfermedades". En: Diario El País. Madrid, edición del 13.06.2013.

9 En España, entre las prohibiciones absolutas de patentar que se establecen en el artículo 1 de la Ley 10/2002, se incluye las invenciones que se consideran contrarias a la moral o el orden público como los procedimientos de clonación de seres humanos, los de modificación de la identidad genética germinal o los que impliquen la utilización de embriones humanos con fines industriales o comerciales. (Casado, María: "Implicancias ético-jurídicas de las patentes biotecnológicas". En: Mayor Zaragoza, Federico y Carlos Alonso Bedate (coords.). Gen-ética. Madrid:Editorial Ariel, 2003, p. 194). 
Lo que sí reconoce la sentencia es el derecho de la empresa Myriad a patentar productos artificiales derivados del gen (ADN sintético), aunque su uso hoy ya no es tan relevante como antes.

Es de notar -citando a Aparisi y López Guzmán-, que la concesión de patentes de organismos vivos o de sus partes, empezó con la oposición del Derecho a conceder patentes de variedades de plantas, animales o procesos biológicos esenciales para su producción. Sin embargo, desde el año 1978, al entrar en vigor la Convención de Munich sobre patentes europeas, comenzó una nueva etapa para otorgar patentes de seres vivos, promovida especialmente en Estados Unidos y extendida luego a Europa. Ahora bien, una cuestión importante que se plantea es si, detrás de este cambio de perspectiva, se encuentra una real preocupación por la salud de las personas o si están más bien las necesidades económicas de la industria farmacéutica. ${ }^{10}$

Estimamos con los citados autores, que así como no puede valorarse igual la concesión de patentes de genes humanos que la de genes de animales y especies transgénicas, es evidente también tener presente que el ser humano no puede ser objeto de propiedad, dada su naturaleza y dignidad, agregando que debe tenerse en cuenta que la investigación científica debe estar inspirada fundamentalmente en una vocación de servicio a la humanidad, por lo que es cuestionable la consagración legal de cualquier patente que desvirtúe esta finalidad. ${ }^{11}$

Ello, obviamente, no niega la posibilidad de que la investigación científica permita obtener determinados provechos económicos, pero siempre y cuando no se desvirtúe esa fundamental finalidad. Como señala el artículo 2.d) de la Declaración Universal sobre Bioética y Derechos Humanos de la UNESCO, debe reconocerse la importancia de la libertad de investigación científica y las repercusiones beneficiosas del desarrollo científico y tecnológico, destacando al mismo tiempo la necesidad de que esa investigación y los consiguientes adelantos se realicen en el marco de los principios éticos enunciados en dicha Declaración y respeten la dignidad humana, los derechos humanos y las libertades fundamentales.

10 Aparisi Miralles Angela y José López Guzmán. "Biotecnologías y patentes: ¿Reto científico o nuevo negocio?". En: Cuadernos de Bioética 1999/2. Madrid. Publicado en: http:/ / aebioetica.org/revistas/1999/2/38/282.pdf, p. 286.

11 Ibid. 286. Frente a todo lo expuesto, Aparisi y López Guzmán plantean el reto de buscar el equilibrio entre el beneficio económico que permita subsistir a los laboratorios y la función social de la investigación y de la propiedad privada. 
Tal concepto se ve reforzado cuando la misma Declaración señala que, tratándose de decisiones adoptadas o de prácticas ejecutadas por aquellos a quienes va dirigida, se habrán de respetar diversos principios, empezando por enumerar en su artículo 3 , los siguientes:

\section{"1. Se habrán de respetar plenamente la dignidad humana, los derechos humanos y las libertades fundamentales.}

2. Los intereses y el bienestar de la persona deberían tener prioridad con respecto al interés exclusivo de la ciencia o la sociedad." ${ }^{12}$

No es fácil, ciertamente, abordar estos temas, teniendo en cuenta su complejidad y alcances. Es así que, como observa María Casado, cuando se habla, por ejemplo, de que la protección legal de la patente se da a la invención, pero no se extiende al descubrimiento, se hace difícil en bioética distinguir en qué circunstancias hablamos de lo uno o de lo otro. Sin embargo, la sentencia europea constituye una rica e interesante pauta de referencia, para la no comercialización del ser humano, lo que es esencial como fundamento del sistema jurídico.

En materia de patentes, no se puede dejar de atender la cuestión del acceso al genoma humano. Desde un punto de vista estrictamente humanista, solidario y de responsabilidad social, no cabe duda que el genoma es patrimonio de la humanidad, mas queda siempre el problema de cómo hacer para que ello no derive en desincentivar el interés de la empresa privada en el desarrollo tecnológico (piénsese nomás en el decisivo aporte del sector privado a efectos de impulsar la carrera para el conocimiento del genoma humano, a tal extremo que el proyecto internacional Genoma Humano tuviera que adelantar la presentación de sus resultados para hacerlo conjuntamente con la empresa privada Celera Genomics, antes que ésta lo adelantara).

\footnotetext{
12 Sin embargo, como anota Corral "si se rechaza que el embrión humano sea persona, se echa por tierra el argumento, como hábilmente ha maniobrado la Corte Interamericana de Derechos Humanos en su sentencia de 28 de noviembre de 2012 -que resuelve el caso Artavia Murillo y otros vs. Costa Rica, en cuanto que en ese país está prohibida la fecundación in vitro-, que, tras resaltar que en el caso Vo, vs. Francia, el Tribunal Europeo de Derechos Humanos, en su sentencia del 8 de julio de 2004, indicó que la potencialidad del embrión y su capacidad para convertirse en una persona requiere de una protección en nombre de la dignidad humana, sin convertirlo en una persona con derecho a la vida, concluye que las tendencias de la regulación en el Derecho Internacional no llevan a la conclusión de que el embrión sea tratado de manera igual a una persona o que tenga un derecho a la vida". Sin embargo, la sentencia que analizamos tiene una visión distinta de la protección del embrión humano, lo que resalta su trascendencia. (Corral García, Eduardo. Op. cit., p. 241). Se pregunta el mismo autor si la sentencia le confiere el carácter de persona al embrión, contestando que ello "no se afirma claramente, pero es obvio que es un ser dotado de dignidad suficiente como para no ser utilizado como un mero objeto" (Ibid. 241).
} 
Siendo el genoma humano patrimonio de la humanidad, y parte de una nueva generación de derechos humanos, los conocimientos alcanzados en la materia no pueden reservarse solo a un grupo de países, por lo que conviene establecer procedimientos que, aceptando el sistema de patentes en sus puntos básicos, permitan que su explotación no genere beneficios exorbitantes para las empresas -que son las que después de financiar las investigaciones se apropian de los beneficios que de ellas se derivan-, en detrimento de los más desfavorecidos y protegidos." 13

El hecho de quedar claro que, de ninguna manera, deba aceptarse patentar genes humanos, no impide reconocer otro tipo de patentes vinculadas con la salud del ser humano, siempre que exista un fin justificado amparado por medios legítimos (no el simple interés empresarial o la satisfacción de la curiosidad científica), se tenga en cuenta la preservación del medio ambiente (sin dejar de reconocer que ello pueda a veces ser algo subjetivo), se actúe prudentemente (es decir, "phronéticamente", recordando el concepto griego de phrónesis) y, por supuesto, se respete siempre la dignidad y la integridad del ser humano.

\section{REFERENCIAS}

Aparisi y López Guzmán, José (1999). “Biotecnologías y patentes: ¿Reto científico o nuevo negocio?. En: Cuadernos de Bioética 1999/2. Disponible en Internet: http://aebioetica.org/revistas/1999/2/38/282.pdf. Consultado el 20 de octubre de 2013.

Aznar, Justo y Luis Miguel Pastor. Estatuto biológico del embrión humano. Dis pon i b l e $n$ I $\mathrm{nternet}$ : http://intranet.usat.edu.pe/aulavirtual/file.php/6698/Material_Estatuto_embri on/3.pdf p. 2. p.4. Consultado el 20 de octubre de 2013.

Casado, María (2003) “Implicancias ético-jurídicas de las patentes biotecnológicas". En: Mayor Zaragoza, Federico y Carlos Alonso Bedate (coords.). Gen-ética. Madrid, Editorial Ariel.

13

Casado, María. Op. cit. p. 199-200. 
Corral García, Eduardo (2013). "El lenguaje bioético en la normativa y jurisprudencia sobre problemas biojurídicos". En: Cuadernos de Bioética XXIV 2013/2. Disponible en internet: http://www.aebioetica.org/revistas /2013/24/81/239.pdfConsultado el 20 de octubre de 2013.

López Moratalla, Natalia; Esteban Santiago y Gonzalo Herranz Rodríguez (2011) "Inicio de la vida de cada ser humano. ¿Qué hace humano el cuerpo del hombre?, En: Cuadernos de Bioética XXII, 2011/2, pp. 286, 287, 288 y 298.

Pastor García, Luis Miguel. "La ciencia y la bioética en el debate embrionario". Artículo publicado en Verdad.es, Murcia. Disponible en internet: http://www.laverdad.es/murcia/prensa/20081115/opinion/ciencia-bioeticadebate-embrionario-20081115.html. Consultado el 15 de noviembre de 2008.

Serra, A. (2004). “Dignidad del embrión humano", en: Consejo Pontificio Para La Familia, Lexicón. Términos ambiguos y discutidos sobre familia, vida y cuestiones éticas, Madrid: Palabra.

Unger, Tomás. (2013) "Los genes y las patentes". En: Diario El Comercio Lima, edición del 09.07.2013, p. A 14. 